\title{
The Effect of Vodcasting Tasks on EFL Listening Comprehension Progress in an Online Program
}

\section{Sajad Faramarzi}

English Department, Isfahan (Khorasgan) Branch, Islamic Azad University, Isfahan, Iran, sajadfaramarzijj@gmail.com

Hossein Heidari Tabrizi

Assoc. Prof., corresponding author: English Department, Isfahan (Khorasgan) Branch, Islamic Azad University, Isfahan, Iran, heidaritabrizi@gmail.com

\section{Azizeh Chalak}

Assoc. Prof., English Department, Isfahan (Khorasgan) Branch, Islamic Azad University, Isfahan, Iran, azichalak@gmail.com

Video podcasting technology or vodcasting is a burgeoning technological advancement which can make computer assisted language learning more convenient. Video technology is extensively used in traditional L2 classrooms. Yet, video podcasting together with the application of meaningful, logical, reasonable, and challenging tasks is rarely used in distance language learning programs. The purpose of this study was to examine the effect of video podcasting tasks on listening comprehension progress of Iranian intermediate learners. For this aim, a quasi-experimental design was used to examine the efficacy of these tasks on a group of 120 English learners. The treatment took twelve weeks and it comprised of working on online vodcasting tasks from five different genres. Paired samples t-test was utilized to assess the amount of listening achievement and the test-taking performance by comparing the results of the pre-test and the post-test. The results demonstrated a statistically significant increase in listening comprehension scores from pre-test to post-test. The magnitude of the difference was calculated by the Eta squared statistic which indicated a large effect size. It was concluded that the superior performance of the learners was contributed to the association of vodcastsing tasks. In addition, Pearson's Product-Moment Correlation was used which revealed a significant positive relationship between participants' engagement rate with Vodcasting Tasks and their test performance.

Keywords: e-learning, listening comprehension, online learning, podcasting, video podcasts, vodcasting 


\section{INTRODUCTION}

Listening plays a critical role in second and foreign language acquisition and it is considered as a crucial means of L2 acquisition; accordingly, the development of listening as a major skill should be regarded as a significant priority in language pedagogy (Norouzi, 2006). The practice of improving listening comprehension has traditionally been accomplished in classroom exercises by a variety of different approaches by highlighting the urgency of paying attention to the listening skill and its sub skills like pronunciation and stress (e.g. Baltova, 1994; Kellerman, 1990; Kellerman, 1992; Progosh, 1996; Shin, 1998; Sueyoshi \& Hardison, 2005; Wagner 2010b).

The advent of technological advances has opened tremendous ground-breaking horizons for implementing diverse instructional styles, some of which are really pioneering and revolutionary, to the benefit of facilitating the process of education in general and language learning in particular. With the ever increasing use of modern technology in distance language learning curricula, the electronic instructional approaches or so called E-learning programs have received immense popularity and admiration among educators, curriculum developers and learners alike. This style of learning proved to be prevalent among different groups of society simply because it minimizes the burdens and hurdles of traditional classes in which one needs to be physically involved (Faramarzi \& Bagheri 2015).

Podcasting technology is literally functioning by simply delivering Really Simple Syndication, RSS, feeds to subscribers. What this high-tech innovation offers is the flexibility in delivering the materials and the convenience for users to have permanent access to learning materials in order to study and practice at any time. Nowadays, the technological advances are making it much easier for both language learners to receive the learning materials via social media and researchers to carry out the experiment and gather their required information.

The foremost rationale behind choosing Vodcasting tasks is its tremendous space for innovation which has received marvellous support from many academicians in the field of E-learning and Web-based communication (e.g. Takeda, 2014) There are many untapped potentials that can be very thought-provoking for many researchers and scholars. In other words, this area is still burgeoning from its roots and has a long way to go to achieve its ultimate objectives. The previous studies, mostly lacking any justification to a theoretical aspect of second language acquisition, haphazardly focused on the transmission of some arbitrarily selected audio materials to observe the amount of students' overall involvement within a short period of time. To clarify the point, in many earlier studies on podcasting, the researchers mostly followed one-shot designs to come up with quantitative and numerical results without spending quality time for the treatment period which is very crucial in yielding any verifiable outcome.

Besides, the collaborative learning has been a missing ring in many former studies. To put it more simply, measuring learners' progress separately without considering the collaborative nature of this technology is resulted in overlooking the core competency of 
this device. The treatment time is also of prime importance since many unexpected things can occur throughout this period and many challenges can emerge as well. Yet, this study intended to approach the issue within a process-oriented schema to obtain the most verifiable pieces of evidence derived from the direct monitoring and analyses of students' performance.

It is also necessary to mention that in all prior podcasting research studies, the accessibility of RSS feeds highly depended on subscribing to specific websites and bookmarking them in your device. Now with the accessibility of Telegram application around the world, there is no need to subscribe to any particular website. In other words, it is free and it does not need any programming to make and/or manipulate RSS feeds. The project was essentially carried out by establishing a specific online group for participants as the main venue of instruction and present the selected materials to the participants. Thereby, students could download and permanently store the materials in their devices. In case of losing the information on smartphones and laptops, the information was stored in the permanent cloud section of the application which let users retrieve them at any time. The role of the instructors was not undermined as they were available all the time for any technical problem to be solved.

\section{LITERATURE REVIEW}

\section{The Theoretical Background}

Communicative approaches received a lot of attention by highlighting the urgency to use the language materials in authentic situations. These methods and approaches which had their roots in the communicative competence and the mental faculty of language learners have been popular to this day. Among those approaches, Task-Based Language Teaching (TBLT) is still the focal point of substantial consideration. This method emphasizes the application of meaningful, reasonable and challenging tasks in a language acquisition process which ultimately encourages learners to interact with each other in a student-cantered classroom (Bowen, 2010; Larsen-Freeman \& Anderson, 2015; Willis \& Willis, 2001). Task-based language learning encourages learners to be more independent and provides a friendly atmosphere to develop critical thinking.

Task-Based Language Teaching endorses creativity and innovation in delivering the tasks. The authentic nature of the method necessitates using the most popular trend of education which is virtual societies. Likewise, highly-technological advances have drastically changed the studying habits of L2 learners. By getting assistance from different innovative and creative technologies such as blogs, wikis, portfolios, games, online applications, virtual societies, etc., researchers can minimize the affective barriers and promote collaborative learning in a friendly motivating environment.

The Task-Based Language Teaching also supports the collaborative learning and this is in absolute accordance with the fundamentals of instruction with video podcasting technology. Therefore, the development of video podcasting tasks and providing an online venue for the students to be involved in a pure distance language learning program can be a giant leap forward for achieving the real potentials of vodcasting technology in computer assisted language learning. 


\section{Podcasting in Traditional L2 Classes}

There were some academicians who investigated the different functionality of visual and pictorial modalities of listening comprehension tests (e.g., Faramarzi, Elekaei, \& Biria, 2015; Wagner 2010a). Yet, no reputable examination syndicate or educational testing service has ever tried to incorporate video materials into their listening tests so far; perhaps due to the fact that using video materials during the test may result in distraction (Bejar et al., 2000).

The diversity and originality of variables and factors allow researchers to easily manoeuvre on these areas and as a result, the research in this area is burgeoning. In several previous studies (e. g., Abdous et al., 2009; Berry, 2006; Chester et al., 2011; Copestake, 2006; Chan and Lee, 2005; Faramarzi, Elekaei \& Koosha, 2015; Hargis \& Wilson, 2005; McGarr, 2009; O’Bryan, \& Hegelheimer, 2007) the use of podcasting technology have been investigated in different situations. McGarr (2009) underscored that this approach can be implemented in many academic contexts for substitutional and supplementary means. In this research on higher education, major aspects of podcasting technology such as 'creativity' and 'accessibility' had been elaborated which had to be used as a supplementary feature in university courses. On one hand, language learners could have a better understanding of language resources presented via podcasting by revising and repeating them as much as they like. On the other hand, by considering podcasting technology as a supplementary tool, the instructor could add more materials in form of video, audio, PowerPoint presentation, workshop results etc., to the main curriculum. Students can also be invited to produce their own podcasts and/or video podcasts which will both inspire them to be actively engaged with the program and demonstrate their real core competencies (Takeda, 2014, Faramarzi, 2018)

Allan (2007) conducted a study to work on the usefulness of podcasting technology in vocabulary building of German vocabulary lists. The podcasting websites were created to provide a memorization path for 28 British learners. The online platform received a great admiration and was used extensively by the learners.

Another study which demonstrated the students' willingness to deliver the podcasting materials on their PCs was done by Chan, Chen, and Dopel (2011). In this paper, 225 university students received 14 podcasting lessons during a 13-week treatment period. Grammar, listening comprehension and cultural differentiation were focused. Students' feedback to lessons was positive and constructive.

In a different study, Ducate and Lomicka (2009) compared the use of podcasting in an integrated classroom. Four different podcasting projects among 68 university students of German and French as second languages were organized. Students created their own podcasting tasks in two projects and integrated them with their blogs. The results showed that students were really satisfied about experiencing the podcasting technology but all listening exercises was downloaded and practiced on their personal computers.

Receiving the podcasts alone cannot guarantee the success of learners in any language learning program. The method of delivering the language materials along with educating the students on how to get involved is very important. For instance, Palalas (2009) 
found that in spite of positive attitudes of students towards the program as a whole, there were little peer connection among the participants and in many cases resulted in rote memorization of words. The meaningful internalization of language learning materials requires an integration of different resources such as audio, video, written files and animated ones. There are a number of studies on the effect of podcasting on vocabulary building as well (Borgia, 2010; Putman \& Kingsly, 2009). Therefore, the current study focused on the potential weaknesses of the previous approaches and sought to carry out the experiment in a new direction.

\section{Podcasting in Modern E-learning Classes}

Recent studies have also included podcasting technology in the spotlight. The effect of podcasting technology on developing vocabulary was recently investigated by several researchers (e.g. Elekaei, 2018; Ghobadi \& Taki, 2018; Heidari Tabrizi \& Onvani, 2018; Khodarahimi \& Heidari-Shahreza, 2018; Movafagh Ardestani, 2017). In almost all of these studies, the learners could achieve a greater degree of vocabulary gain and vocabulary retention. The positive effect of podcasting on grammar was also studied by Nabati (2018). Moreover, its marvellous effect on reading comprehension was studied by Azadi and Azad (2017). Faramarzi (2018) investigated the integrated nature of video podcasting and its efficacy on developing integrated skills. Attitudes towards podcasting technology-which were predominantly positive in many cases- was the subject of many studies (e.g. Karimov \& Kim, 2017; Faramarzi, Heidari Tabrizi, and Chalak, submitted manuscript, 2018a; Khoshsima, Saed, \& Arbabi, 2018)

As long as podcasting provides a good opportunity for students to refurbish the learnt materials and/or prepare themselves before the lectures, Heydarpour et al (2013) investigated the adequacy of podcasting on the performance and attitudes of students of medicine. The study, conducted in Tehran University of Medical Sciences, tried to scrutinize the acceptability rate of podcasting in pharmacology classes which involved long lectures, lectures which necessitates the absolute concentration in the class. As far as students of medicine are under the tension of preparing themselves for the upcoming lectures, making sense of what is going on in each class, and catching up with the massive amount of revisions, podcasting proved to be really stimulating as $46 \%$ of students downloaded all lecture pods regularly and $96 \%$ of students believed that podcasting had an undeniably positive impact on course preparation. Similarly, in an online article, Nozari and Siamian (2015) found similar results that utilizing podcasting technology can significantly motivate students in the high school.

The study of podcasting as mentioned before, is closely correlated with cross-cultural sensitivity and developing a sense of cooperation among different walks of life. Zarei, and Ghasemi (2016) focused on the suitability of podcasting advancement on enhancing the collaborative spirit of students of psychology at Allameh Tabatabaei University in Tehran. The positive results of this study confirmed the podcasting potential in developing "individual responsibility acceptance, group processing, social skills and interaction in collaborative learning" (p.5)

The issue of peer-correction in elevating the speaking ability of IELTS students was also 
studied by Sarajian and Aminloo (2016). The findings of their study revealed that correcting voice messages by peers through the use of podcasting can significantly support the speaking ability. Likewise, many other advantages of podcasting technology have been concluded by Khanghah and Halili (2015) as they investigated the effectiveness of podcasting on vocabulary enhancement of Iranian students. The researchers emphasized the flexibility feature of podcasting and remarked that this is a tool which can assist the curriculum process more conveniently. Furthermore, it is a device which makes students independent as it precludes the necessity of getting help from peers. Neither do students have the obligation to repeat the same question inside the class. Therefore, more time is saved to intensively focus on the learning materials. Additionally, it is very user-friendly that it does not require technical skills and expertise.

As far as the technical side of learning language skills is considered, in a more recent study on vocabulary enhancement of Iranian students, Hosseini and Choobdari (2017) analytically examined the role of podcasting on Iranian students' level of vocabulary through organizing podcasting tasks for the experimental group and the traditional task types for the control group. After exposing to a 24-hour instruction as the treatment, the results of the t-test showed that the performance of the experimental group significantly outweighed the control group. Students' attitudes and feelings were correspondingly positive.

\section{Perceptions and Attitudes towards Podcasting}

Despite the mixed reactions towards the podcasting technology in previous studies, researches are still trying to find the major potentials and challenges of this pedagogical approach. As for the motivating features, a study done by Chan, Chi, Chin, and Lin (2011) revealed the positive attitudes of participants which was measured by questionnaires and semi-structured interviews. Similarly, a longitudinal study by Martin and Beckman (2011) demonstrated a high approval rate of learners studying Spanish. The researchers referred to the podcasting as a 'pedagogically-sound model'

Regarding the attendance problem of traditional classes, podcasting was considered as a substitutional and a supplementary tool. Berry (2006) accredited podcasting with features like its portability, intimacy, and accessibility. Hence, providing a sound model for promoting the integrated skills in SLA remains to be a problem. According to Hargis and Wilson (2005), "podcasting can promise a unique approach [to] improving foundational pedagogical approaches to information processing and conceptual learning" (p. 6). Since any novel approach can sound intimidating and obtrusive, this study accentuates the necessity of training instructors and raising learners' awareness on how to use of the technology in the best possible way.

Affective barriers that can be threatening to start any kind of innovative experience may indeed hinder the process of learning. For example, Chan and Lee (2005) argued that using podcasting technology as an adjunct tool can considerably minimize the level of anxiety. Similarly, Williams and Michael (2007) clearly demonstrated that $71 \%$ of students reviewed the podcasting materials regularly and reflected upon their 
experiences as comfortable and user-friendly. Their reasons are also worth mentioning. The majority of participants chose this method because of interference of language classes with other classes and as a result, no class was missed by subscribing to a particular podcasting provider. It seems that the capacity to access pedagogical materials can manifest itself more than any other characteristic which by itself accentuates the consistency of podcasting in language learning.

Muppala and Kong (2007) focused on the problem-solving feature of podcasting as they received marvelous feedback from their students concerning the areas they experienced difficulty. In another study by Bolliger, supankom, and Boggs (2010), the learners regarded podcasting as a tool to minimize the physical distance between learners and the instructor and also as a great tool to maximize the collaborative learning among peers. Consequently, it removes the artificial boundary lines among students. Also, the interactive environment can indeed provide a great venue to negotiate meaning

In a different study by Faramarzi, Heidari Tabrizi, and Chalak (submitted manuscript, 2018) major issues of video podcasting were investigated. It was concluded that participants expressed a great sense of satisfaction with the presentation style of vodcasting to promote integrated L2 skills. It also assisted learners to be more independent and more willing to continue the project which involved using video podcasts in improving integrated skills.

Investigating the reasons of why some learners use or avoid using podcasting was shown by Chester et al. (2011) who compared podcast users with non-users and stated that those who spent time reviewing the language learning materials via podcasting had a higher level of self-efficacy. Podcasting users referred to the usefulness and convenience of the podcasting materials as an adjunct tool to catch up with the real pace of instruction. Nevertheless, the non-users had their own reasons for evading the technology as many of them still preferred the real face to face interaction with their teachers and peers inside the classroom. Hence, many of them remained to be dubious about how to practice podcasting appropriately.

\section{Research Questions}

The present study addressed the following research questions:

Q1: Does implementing Vodcasting tasks (VTs) have any effect on the Iranian intermediate EFL learners' listening comprehension progress?

Q2: Is there any correlation between the amount of participants' engagement rate with VTs and their test performance?

\section{METHOD}

\section{Design}

The current study attempted to employ a pre-test/post-test only design with a long term treatment as the major part of the program. The foremost rationale for selecting such a design was because it was not desirable to randomly assign treatments to participants 
individually. Randomization of samples is mostly ideal for fully-experimental designs in which samples are chosen randomly for control and experimental groups. (Shandish, Cook, \& Campell, 2000).

However, this study focused on the effectiveness of treatment on one homogenous group through a specific period of time which had been allotted for the treatment via an Elearning platform. Likewise, a pre-test/post-test approach was chosen to measure the effect of treatment. Consequently, in order to avoid the test bias and the artificial improvement, it was tried to select both tests of equal difficulty and care was taken in administering the tests. Last but not least, the Pearson-product Moment correlation was utilized to obtain the relationship between the engagement rate in form of engaged hours with vodcasting and the amount of progress in form score difference. In other words, this statistic was utilized to measure the long-term effect size of the treatment and find a correlation between the results and the effect of the treatment.

Participants were selected among undergraduate students of English translation at Karaj Branch of Islamic Azad University, Iran. The sampling process followed non-random purposive sampling procedure with minimum requirement of language proficiency score. The design of the study required working with 120 students who were in accordance with the criterion of taking part in the research program. At the beginning of the experiment, 300 students were invited to take the proficiency test which acted as the placement test as well. Among the participants, 120 students who had received the minimum requirement of 60 out of 120 scores of TOEFL iBT proficiency test that is $50 \%$ of the scores, were selected as the intermediate-level students. This criterion was in accordance with the Common European Framework of References, CEFR.

The participants were selected from university students in a coeducational system. Their ages ranged from 18 to 30 and they lived most of their lives in Iran. Persian was their first language and they studied English as a foreign language as part of the requirement for getting the Bachelor's degree in English translation program.

\section{Instruments and Materials}

\section{Vodcasting Tasks (VTs)}

A series of 20 Video podcasting tasks or VTs were presented to participants which comprised of grammar learning vodcasts; vocabulary building vodcasts; documentary vodcasts; lecture vodcasts; and News vodcasts. The grammar sections demonstrated the application of grammatical topics in video files which presented the real use of grammar points in everyday conversations. These Vodcasting tasks were designed to educate participants with contextualized form of grammar.

The vocabulary tasks also targeted different aspects of word building such as, collocations, phrasal verbs, idioms and informal conversational structures. The tasks aimed at explaining different aspects of authentic English by gradually moving from the graded parts of vocabulary and grammar sections.

Moreover, lecture vodcasts, documentary vodcasts, and News vodcasts were demonstrated the authentic academic contexts and everyday passages. The provided 
tasks were aimed at involving learners to work on major skills and sub skills with listening skill in the spotlight. Every vodcasting task was accompanied by a series of questions which necessitated the participants to actively engage in collaborative learning and negotiate the responses together.

\section{Telegram Application}

In order to implement the whole experiment in a pure distance language learning environment, the researchers had to find the best application which was suitable. Telegram application was chosen among many available application for its safety, userfriendliness and tremendous multimedia features. The whole process of exchanging the vodcasting tasks together with the discussion forum was conducted in Telegram by getting help from its incredible features and robots.

One more thing which is worthy of mentioning is that Telegram accommodates the exchange of all types of files to be presented in the main forum of channels and groups.

\section{Pre-test/Post-test}

The pre-test/post-test design of this research required the participants to be in the same level by taking TOEFL iBT proficiency test as the test for both placement and pre-test examinations. The pre-test and the placement test were merged into one united test as it showed the real level of students' listening proficiency and could select the qualified participants. Having considered that, it was irrelevant and impractical to take two consecutive tests of the same nature before starting the treatment. The TOEFL iBT proficiency test with an already established reliability was considered as long as it was in accordance with the integrated nature of the vodcasting tasks.

All the questions in the tests were multiple-choice tests and were designed for both college life situations and the technical academic ones. Besides the integrative nature of the test, all different functions like listening for the main idea, listening for the details, functional questions such as discovering speakers' stance, and the rhetorical question types are all available in the internet-based version of test. The subjects received the post-test with the same level of difficulty for the assumptions of parametric studies to be met and for findings to be as reliable as possible.

\section{Procedure}

The researcher was responsible for obviating the technical and/or educational problems related to the transmission of materials at any time. Moreover, there were many robots which helped students and the researcher to accelerate the instruction process and data collection. Understanding how these robots work and their literacy was imperative as well.

After selecting the intermediate participants through the proficiency test, a listening pretest was administered to record the current level of listening achievement. There was only one group and the focus was on the treatment itself which involved working on vodcasting tasks online. During the treatment period, different days of the week were specified for different activities. On Saturdays, one Vodcast explaining a grammar point 
were presented to the students. The length of each grammar pod was 10 minutes and they have been extracted from the official British Council website. On Sundays, 10minute Vodcasts targeting the vocabulary were presented to the participants. The participants received documentary Vodcasts on Tuesdays which lasted for 20 minutes in each pod and extracted from the Australian Network website. Lecture Ready vodcasts were presented on Wednesdays. The amazing 10-minute academic lectures were extracted from Lecture Ready Series published by Sarosy and Sherak (2013). Finally, on Thursdays, participants were exposed to a 10-minute news of the day from different sources, mainly from $\mathrm{CNN}$ and BBC.

Then after accomplishing different parts of the treatment stage including receiving the videos and their exercises and doing the assigned tasks and negotiating them with other members, a post-test was given to students to measure the listening achievement after the treatment period.

\section{Data Analysis}

The performance data were collected by taking pre-test and post-test before and after the treatment and were arranged in form of scores. The observational data are collected by getting the information for the number of hours each participant is spending to engage in the experience itself which was inquired directly from the participants. To confirm the impact of the treatment, it was attempted to find the correlation between the amount of progress in form of scores and the viewing rate in form of hours.

In the twelfth week and after finishing all the assigned video podcasts, the post-test was administered and the results were recorded. After collecting the data from different resources, it was essential to use the best measurement system. A paired samples t-test, also known as repeated measures t-test, was utilized to assess the amount of listening achievement and the test-taking performance before and after the treatment.

The overall significance of the t-test was calculated by IBM SPSS Statistics version 20 software which is demonstrated in the Sig. (2-tailed) column of tables 2 and 3. The effect size of the paired sample t-test was also needed since it gave us substantial information about the magnitude of the treatment. Accordingly, Eta Squared were analysed for this section because it is one of the most commonly used measures to determine the effect size.

Moreover, in order to analyse the relationship between Vodcasting viewing rate and listening comprehension achievement, the Pearson's product-Moment Correlation was used. Pearson's formula is more preferable since it can display the magnitude of linearity.

\section{FINDINGS AND DISCUSSION}

\section{Response to the First Question}

The first research question sought to investigate the effect of implementing Vodcasting Tasks (VTs) on Iranian EFL intermediate learners' listening comprehension. To answer this research question, a paired-sample t-test was used. Table 1 illustrates the descriptive 
test statistics of pre-test and post-test for implementing the Vodcasting Tasks on listening comprehension.

Table 1

Descriptive Test Statistics for Listening Comprehension

\begin{tabular}{llll}
\hline & Mean & $\mathrm{N}$ & Std. Deviation \\
\hline Pre-test Scores & 13.03 & 120 & 2.827 \\
Post-test Scores & 15.12 & 120 & 3.189 \\
\hline
\end{tabular}

According to table 1, Iranian EFL intermediate learners had higher mean of listening comprehension in post-test $($ mean $=15.12)$ compared to that of the pre-test $($ mean = 13.03). Table 2 demonstrates the paired-sample correlation since it is important to measure how strongly pre-test and post-test scores are associated with one another regarding implementing Vodcasting Tasks. Conferring to table 2, pre-test and post-test scores are highly and positively correlated $(r=.689, p<.0005)$ which means there is a positive correlation between the scores participants received in the post-test and the effect of the treatment.

Table 2

The Paired-Sample Correlation between Pre-test and Post-test Scores

\begin{tabular}{llll}
\hline & $\mathrm{N}$ & Correlation & Sig. \\
\hline $\begin{array}{l}\text { Pre-test Scores } \\
\begin{array}{l}\text { Post-test Scores } \\
\hline\end{array}\end{array}$ & 120 & .689 & .000 \\
\hline
\end{tabular}

Table 3 shows the paired-sample t-test for the effect of implementing Vodcasting Tasks (VTs) on Iranian EFL intermediate learners' listening comprehension. Regarding tables 1 and 3, there is a statistically significant increase in listening comprehension scores from pre-test $(M=13.03, S D=2.82)$ to post-test $[M=15.12, S D=3.189, t(119)=9.57$, $p<.0005]$. The magnitude of the difference was calculated by the Eta squared statistic. The Eta squared statistic presented in table 3 indicated a large effect size. Therefore, the implementation of VTs has a significantly positive effect on listening comprehension of Iranian intermediate EFL learners.

Table 3

The Paired-Sample T-Test for the Effect of Implementing Vodcasting Tasks

\begin{tabular}{|c|c|c|c|c|c|c|c|}
\hline & \multicolumn{4}{|c|}{ Paired Differences } & \multirow[b]{3}{*}{$\mathrm{t}$} & \multirow[b]{3}{*}{ df } & \multirow[b]{3}{*}{$\begin{array}{l}\text { Sig. (2- } \\
\text { tailed) }\end{array}$} \\
\hline & \multirow[b]{2}{*}{ Mean } & \multirow[b]{2}{*}{$\begin{array}{l}\text { Std. } \\
\text { Deviation }\end{array}$} & \multicolumn{2}{|c|}{$\begin{array}{l}\text { 95\% Confidence Interval of } \\
\text { the Difference }\end{array}$} & & & \\
\hline & & & Lower & Upper & & & \\
\hline $\begin{array}{l}\text { Pre-test Scores - } \\
\text { Post-test Scores }\end{array}$ & 2.092 & 2.394 & -2.524 & -1.659 & $\begin{array}{l}-5.571 \\
\end{array}$ & $\begin{array}{l}11 \\
9\end{array}$ & .000 \\
\hline
\end{tabular}

\section{Response to the Second Question}

The second research question sought to examine the relationship between participants' engagement (viewing) rate with Vodcasting Tasks (VTs) and their test performance. In other words, in order to further verify the effect of the treatment which was analysed by 
the results of the pre-test and post-test, it was attempted to find a correlation between the progress rate and the amount of time which participants spent on viewing the Vodcasting tasks and engaging in other online activities. The information for the viewing rate was directly asked from participants within a semi-structured interview. To answer this research question, a Pearson's Product-Moment Correlation was used. Table 4 shows the results of the correlation procedure for participants' engagement with Vodcasting Tasks and their test performance.

Table 4 shows that, there is a significant positive relationship between participants' engagement with Vodcasting Tasks (VTs) and their test performance $(r=.914, n=$ $120, p=.000$ ). As a result, there is a positive correlation between the amount of participants' engagement rate with VTs and their listening achievement.

Table 4

Correlation between Participants' Engagement with Vodcasting Tasks (VTs) and Their Test Performance

\begin{tabular}{lllll}
\hline & & $\begin{array}{l}\text { Participants' } \\
\text { with VTs }\end{array}$ & $\begin{array}{c}\text { Engagement } \\
\text { Post-test } \\
\text { Scores }\end{array}$ \\
\hline $\begin{array}{lll}\text { Participants' } \\
\text { with VTs }\end{array}$ & Engagement & $\begin{array}{l}\text { Pearson } \\
\text { Correlation }\end{array}$ & 1 & $.914^{* * *}$ \\
& $\begin{array}{l}\text { Sig. (2-tailed) } \\
\mathrm{N}\end{array}$ & 120 & .000 \\
& & & 120 \\
\hline
\end{tabular}

**. Correlation is significant at the 0.01 level (2-tailed).

The results of this study strongly supports the findings of the study made by Hosseini and Choobdari (2017) which observed the role of podcasting on Iranian students' level of vocabulary. As for the vocabulary building, podcasting technology has also been proved as positive by Allan (2007) The positive findings of this research is also in accordance with the findings of a study made by Sarajian and Aminloo (2016). The findings of that study revealed that correcting voice messages by peers through the use of podcasting can significantly support the speaking ability.

Moreover, the positive results of this study is in complete harmony with the research made by Heydarpour et al (2013) which highlighted the course preparation feature of podcasting technology.

However, the current findings in this study absolutely reject the findings of Palalas (2009) which found little peer connection among the participants and in many cases resulted in rote memorization of words

The significant results of the pre-test/post-test is in agreement with the results of Chan, Chen, and Dopel (2011) which focused on the positive and constructive impact of podcasting on the development of grammar, listening comprehension and cultural differentiation.

\section{CONCLUSION AND IMPLICATION}

This study was a preliminary investigation into how video podcasting technology can improve the EFL learners' listening comprehension ability through interaction with 
video podcasting tasks, and the extent to which the amount of exposure can affect the progress rate. Clearly, these results are not conclusive, and more research is necessary. Even after recognizing its weaknesses and limitations, however, this study does provide some theoretical and practical insight which corroborated the superiority of video podcasting technology

The results of the present study revealed a positive effect of the treatment in enhancing the listening proficiency of Iranian intermediate EFL learners. The statistical significance of the effect size of the pre-test and the post-tests clearly proves the superiority of the treatment as a major advantage in this experience. The positive effect of the treatment can be resulted from various reasons which are stemmed from the nature of the treatment itself

First, the integrative nature of the podcasting technology by itself, can easily change the style of presenting the materials in a way that it can focus on different skills at the same time. This issue has been confirmed by Abdous et al. (2009). Second, podcasting technology as a whole and its different version like vodcasting, can be regarded as a logical method for instruction in a pure distance language learning program. This is in accordance with what had already been specified by Martin and Beckmann (2011) as a 'pedagogically-sound model'. Also, Hargis and Wilson (2005) declared that podcasting can promise a unique approach to improve foundational pedagogical techniques. Third, the accessible online nature of the application provides an opportunity for everyone to have permanent access to the materials and thus, maximizes the chances of studying and reviewing. This had also been underlined by William and Michael (2007) that no class would be missed by subscribing to a particular podcasting provider. Forth, the online forum provides an excellent opportunity for everyone to get in touch with other peers and the instructor. It is a reminder from Read (2007) that the starting point should be very easy and comprehensible for all learners and according to Allan (2007) education in computer literacy is necessary. Fifth, the interactive and multimodal nature of the Vodcasting tasks provides a path for other skills to thrive and improve. By contextualizing the learning materials in integrative texts, learners have a chance to build up their major skills and sub-skills.

Podcasting technology is a versatile and adaptable tool which fosters the sense of multitasking and specifically it encourages the development of integrative skills for a variety of different purposes including test taking, note-taking, etc. Moreover, the idea of working on video podcasting technology in an online program stimulates the cultural sensitivity which means getting to know different cultural norms and moving towards accepting the cultural differences within a communicative environment.

Furthermore, this approach fosters the punctuality i.e. doing things on time and obeying the instructional rules. Learners can practice taking a leading role of being a self-starter and act as a team player. Therefore, video podcasting technology provides a stress-free situation which lowers the anxiety in learning.

The ongoing assessment is made convenient in video podcasting technology. Likewise, the online environment of different telegram application makes it easier for instructors 
to have a clearer knowledge of what the status of each learner is in any particular moment and thus compensate the losses on the spot. The practice of video podcasting technology is time saving and user-friendly and as a result, students feel confident about using it. In other words, this study demonstrated the idea that video podcasting technology is a robust way of leading classes to be more interactive and studentcantered.

\section{Suggestions for Further Research}

The analysis of the data from the present study has made it possible to suggest some recommendations for forthcoming research regarding the perceptions and attitudes of voddcast users during a test of L2 listening skill. Vodcast users should be asked about different aspects of the technology. Another useful future study would be one which investigated the correlation between test scores and test-takers' vodcasting strategies while taking the test between the learners who score higher on a listening comprehension test and those who score lower on the test. The other useful study would be one that assesses test-takers' awareness of vodcasting strategies such as note taking, and summarization. Asking test-takers to estimate what percentage of the time they place to the strategies, and then comparing these self-assessments with an analysis of the actual time oriented to exposure of the vodcasting tasks themselves. Finally, a study that investigated orienting behavior with different test task characteristics would be informative. The effect of video podcasting in improving the pronunciation of second language learners can also be a subject of enquiry. As far as many online pronunciation applications and robots are available, the instructors can motivate learners to produce native-like models in a collaborative way. Investigating the role of video podcasting in speaking development can also yield interesting results.

\section{REFERENCES}

Abdous, M., Camarena, M., \& Facer, B. (2009). MALL technology: Use of Academic Podcasting in the Foreign Language Classroom. RECALL Journal, 21(1), 76-95.

Allan, S. (2007). Podcasts and Embedded Audio to Support Language Learning. Warwick Interactions Journal, 30(2), 1-12

Azadi, M., \& Azad, M. (2017). On the effect of mobile and electronic learning (ME learning) on reading rate and reading comprehension of Iranian elementary EFL learners. Proceedings of the 15th International TELLSI Conference

Baltova, I. (1994). The Impact of Video on Comprehension Skills of Core French Students. Canadian Modern Language Review, 50, 507-531.

Bejar, I., Douglas, D., Jamieson, J., Nissan, S., \& Turner, J. (2000). TOEFL 2000 listening framework. Princeton, NJ: Educational Testing Service.

Berry, R. (2006). Will the iPod Kill the Radio Star? The International Journal of Research into New Media Technologies. Sage Publication. 12(2) 143-162 
Bolliger, D. U., Supanakan, S. \& Boggs, C. (2010). Impact of Podcasting on Student Motivation in the Online Learning Environment, Computers and Education, 55,714722.

Borgia, L. (2010). Enhanced Vocabulary Podcasts in Fifth Grade Classrooms, Reading Improvement. 46(4), 263-272

Bowen, T. (2010). Teaching approaches: Task-based learning. Retrieved from http://www.onestopenglish.com/section.asp?docid=146502

Chan, W-M., Chen, I., \& Dopel, M. (2011). Podcasting in foreign language learning: Insights for podcast design from a developmental research project. In M. Levy et al. (Eds.), WorldCALL: International Perspectives on computer-assisted language learning (pp. 19-37). New York, NY: Routledge.

Chan, W-M., Chi, S-W., Chin, K-N., \& Lin, C-Y. (2011). Students' Perceptions of and Attitudes towards Podcast-Based Learning: A Comparison of two Language Podcast Projects, Electronic Journal of Foreign Language Teaching, 8(Suppl. 1), 312-335. Retrievable from http://e-flt.nus.edu.sg

Chan, A., \& Lee, M. J. (2005). An MP3 a day keeps the worries away: Exploring the use of podcasting to address preconceptions and alleviate pre-class anxiety amongst undergraduate information technology students. In In DHR Spennemann \& L. Burr (Ed.), Good Practice in Practice: Proceedings of the Student Experience Conference (pp. 58-70). Wagga Wagga, NSW.

Chester, A., Buntine, A., Hammond, K., \& Atkinson, L. (2011). Podcasting in Education: Student Attitudes, Behavior and Self- Efficacy, Educational Technology \& Society. 14 (2), 236-247.

Copestake, S. (2006). How to create your own podcast. Personal Computer World.

Ducate, L. \& Lomicka, L. (2009). Podcasting: An effective tool for honing language students' pronunciation? Language Learning \& Technology, 13(3), 66-86.

Elekaei, A. (2018) Using Vocabulary Podcasts Tasks to Improve Iranian EFL Learners' Vocabulary Gain and Retention in an E-learning Project: Attitude, Autonomy, and Language Learning Strategies in Focus. Unpublished Doctoral Dissertation. Islamic Azad University, Isfahan Branch, Iran.

Faramarzi, S. (2018). The Impact of Vodcasting Tasks on Iranian Intermediate EFL Learners' Listening Comprehension, their Engagement, and their Attitudes in an Elearning Project. Unpublished Doctoral Dissertation. Islamic Azad University, Isfahan (Khorasgan) Branch, Iran

Faramarzi, S. \& Bagheri, A. (2015). Podcasting: Past Issues and Future Directions in Instructional Technology and Language Learning, Journal of Applied Linguistics and Language Research. 2(4), 207-221

Faramarzi, S., Elekaei, A., \& Biria, R. (2015). Investigating Iranian Test-takers' 
Performance over Taking Different Modalities of Listening Comprehension Test. SinoUS English Teaching, 12(5), 327-340.

Faramarzi, S., Elekaei, A., Koosha, M. (2015). New Insights into Distance Language Learning, Journal of Applied Linguistics and Language Research, 2(8), 191-207

Faramarzi, S. Heidari Tabrizi, H. \& Chalak, A. (2018) Learners' Perceptions and Attitudes towards L2 Vodcasting Tasks in an E-learning Project. Manuscript submitted for publication.

Ghobadi, S., \& Taki, S. (2018). Effects of Telegram Stickers on English Vocabulary Learning: Focus on Iranian EFL Learners, Research in English language pedagogy, 6(1), 139-158.

Hargis, J. and Wilson. D. (2005) Fishing for Learning with a Podcast Net. University of North Florida. Retrieved from: http://www.unf.edu/dept/cirt/tech/podcast/Hargis PodcastArticle.pdf

Heidari Tabrizi, H., \& Onvani, N. (2018). The impact of employing Telegram app on Iranian EFL Beginners' Vocabulary Teaching and Learning, Applied Research on English Language, 7(1), 1-18.

Heydarpour, P., Hafezi-Nejad, N., Khodabakhsh, A., Khosravi, M., Khoshkish, S., Sadeghian, M., Samavat, B., Faturechi, A., Pasalar, P., \& Dehpour, A.R. (2013) Medical Podcasting in Iran; Pilot, Implementation and Attitude Evaluation. Acta Medica Iranica, 51(1) 59-61 Tehran University of Medical Sciences, Tehran, Iran.

Hosseini, M., \& Choobdari, B. (2017). The Role of Podcasting in Teaching English Vocabulary to Iranian EFL Pupils. Paper presented in E-learning Conference Seminar. $11^{\text {th }}$ E-Learning Association of Iran.

Karimov, O., \& Kim, H. (2017). Factors of UTAUT Affecting the Use Behavior: Based on Telegram Application in Uzbekistan. Asia-pacific Journal of Multimedia Services Convergent with Art, Humanities, and Sociology, 7(12), 831-840.

Kellerman, S. (1992). 'I see what you mean': The Role of Kinesics Behavior in Listening and Implications for Foreign and Second Language Learning, Applied Linguistics, 13, 239-258.

Kellerman, S. (1990). Lip service: The Contribution of the Visual Modality to Speech Perception and its Relevance to the Teaching and Testing of Foreign Language Listening comprehension, Applied Linguistics, 11, 272-280.

Khodarahmi, Z., \& Heidari-Shahreza, M. A. (2018). Effect of MALL on the Acquisition of Word Stress Patterns of English by Iranian EFL Learners: The Case of Telegram, Journal of Applied Linguistics and Language Research, 5(1), 40-55.

Khoshsima, H., Saed, A., \& Arbabi, M. A. (2018). Online Teachers' Attitudes toward Using Technology in Teaching English as a Foreign Language, Journal of Applied Linguistics and Language Research, 5(2), 134-148. 
Larsen-Freeman, D. \& Anderson, M. (2015). Techniques and principles in language teaching. (3rd Ed.). NewYork, NY: Oxford University Press.

Martin, M., \& Beckmann, E. (2011). Simulating immersion: Podcasting in Spanish teaching. In B. Facer \& M. Abdous (Eds.), Academic podcasting and mobile assisted language learning: Applications and outcomes (pp. 111-131). Hershey, PA: IGI Global. Retrievable from http://www.igi-global.com

McGarr, O. (2009). A Review of Podcasting in Higher Education: Its Influence on the Traditional Lecture, Australasian Journal of Educational Technology, 25(3), 309-321

Movafagh Ardestani, E. (2017). The Effect of Using Telegram Messenger on Vocabulary Learning of Iranian EFL Learners, Language Education Studies, 3(4).

Muppala, JK. \& Kong, CK. (2007). Podcasting and its use in enhancing course content. Computers and Advanced Technology in Education. Retrieved from: http://www.researchgate.net/profile/Jogesh_Muppala/publication/228635455_Podcastin g_and_its_use_in_enhancing_course_content/links/0fcfd5051b02109e13000000.pdf

Nabati, A. (2018). Teaching Grammar through Social Networks and its Effect on Students' Writing Accuracy. Biannual Journal of Applications of Language Studies (JALS), 11(1).

Nozari, A. Y., \& Siamian, H. (2015). The Effect of Applying Podcast Multimedia Teaching System on Motivational Achievement and Learning among the Boy Students, Acta Informatica Medica, 23(1), 29.

Norouzi, M.H. (2006). The Effect of Awareness-raising about Listening Sub-skills on the Iranian EFL Learners' Listening Comprehension. Unpublished Doctoral Dissertation. Tehran University, Iran.

O'Bryan, A., \& Hegelheimer, V. (2007). Integrating CALL into the Classroom: The Role of Podcasting in an ESL Listening Strategies Course, RECALL Journal, 19(2), 162-180.

Palalas, A. (2009). Using mobile devices to extend English language learning outside the classroom. In D. Metcalf, A. Hamilton, \& C. Graffeo (Eds.), mlearn2009: 8th World Conference on Mobile and Contextual Learning Proceedings. Orlando, FL: University of Central Florida.

Progosh, D. (1996). Using Video for Listening Assessment Opinions of Test-Takers, TESL Canada Journal, 14, 34-43.

Putman, S.M. \& Kingsley, T. (2009). The Atoms Family: Podcast to Enhance the Development of Science Vocabulary, The Reading Teacher. 63(2), 100-108

Read, B. (2007). How to Podcast Campus Lectures, The Chronicle of Higher Education, 53(21), 20-32. 
Sarajian, F., \& Aminloo, M. S. (2016) The Effect of Peer-correction Through Podcast on the Improvement of Speaking Skill of Iranian IELTS Students. International Journal of Research in Social Sciences and Humanities. 6(3)

Sarosy, P. \& Sherak, K. (2013). Lecture Ready. Oxford University Press. Oxford, UK

Shandish, W., Cook, T., \& Campbell, D. (2002). Experimental and Quasiexperimental Designs for Generalized Causal Inference. Boston, MA: Houghton Mifflin.

Shin, D. (1998). Using Video-Taped Lectures for Testing Academic Language, International Journal of Listening, 12, 56-79

Sueyoshi, A., \& Hardison, D. (2005). The Role of Gestures and Facial Cues in Second Language Listening Comprehension, Language Learning, 55, 661-699.

Takeda, M. (2014). The effect of podcast tasks on students' engagement and performance in a beginning level Japanese language course. Unpublished Doctoral Dissertation. Western Carolina University, Cullowhee: NC, USA.

Wagner, E. (2010a). The Effect of the Use of Video Texts on ESL Listening Test-Taker Performance, Language Testing, 27 (4), 493- 513.

Wagner, E. (2010b). Test-takers' interaction with an L2 video listening test. System 38, 280-291.

Williams, J., \& Michael, F. (2007). 'Perpetual Connectivity': Lecture Recordings and Portable Media Players. In EdMedia: World Conference on Educational Media and Technology (pp. 3083-3091). Association for the Advancement of Computing in Education (AACE).

Willis, D. \& Willis, J. (2001). Task-based learning. In R. Carter \& D. Nunan (Eds.) The Cambridge guide to teaching English to speakers of other languages, (pp. 173-179). Cambridge, UK: Cambridge University Press.

Zarei. E., \& Ghasemi, S. M. (2016). Podcast Impact on Cooperative Learning of Allameh Tabatabaei University Students, Journal of Information and Communication Technology in Educational Sciences, 2(22) 5-18 